\title{
Fostering A Wholistic Education: A Practical Approach For Advisors
}

H. Richard Priesmeyer, St. Mary's University

Stephanie Ward, St. Mary's University

Mary Ann Murray, St. Mary's University

\begin{abstract}
This article defines wholistic education and provides a model currently used in a college-level, academic setting. The various dimensions of the model are described along with the manner by which each is measured. An important contribution of this paper is the introduction of nonlinear methods which provide appropriate means for analyzing and responding to individual student behaviors. While the model is specific to our institution it is general enough to be adapted to any other academic setting.
\end{abstract}

Keywords: Wholistic Education, Nonlinear, Advising.

\section{INTRODUCTION}

$\mathscr{Q}$

S. News \& World Report Magazine (March 12, 2007) recently reported that 63\% of entering freshmen are taking six years to graduate. The report goes further to question the adequacy of higher education in the U.S. and whether college graduates are really being educated in ways that are valued by its stakeholders - government, parents, employers, and students themselves. The age-old debate about whether a university's goal is to train students to be learned scholars or professional employees is very much alive today. Business education is often identified as a professional training forum without much emphasis on the broader liberal arts curriculum. However, increasing students' critical thinking, logical reasoning, problem solving analysis, and ethical and interpersonal skills are crucial to developing a student who will productively contribute in the business world. Educating business students in a broader manner can be accomplished when we approach business education through a different lens of learning. This paper introduces a model of wholistic education that focuses on a comprehensive approach of developing business students such that today's stakeholders' demands are addressed.

\section{WHOLISTIC EDUCATION}

The term "wholeness" has emerged to describe a new view of complex systems beyond that offered by traditional systems theory. Rather than focusing on the parts of a system, a wholeness view defines parts as only artifacts of a larger whole. The whole is considered primary and the parts secondary with emphasis on understanding the whole. The whole and all the relationships in it dynamically evolve over time [Seigfried, Priesmeyer, Murray, 2004].

Compared to more traditional views, wholeness suggests changes in how one should manage a complex process such as an educational experience. Rather than viewing the education as a collection of "independent parts" the wholeness view calls for it to be managed as one "interdependent whole." The wholeness view draws attention to the interdependencies among the parts and thereby changes the focus of decision-making. Problems are viewed as problems of the whole rather than associated with any single part. Solutions, likewise, emerge from a better understanding of the whole.

John Tagg (2003) and Tagg and Barr (1995) state that the difference between the instruction and learning educational paradigms is that in an instructional paradigm what colleges do is defined by some specified 
methodology or administrative structure while the learning paradigm is defined by what students learn and do. The learning paradigm broadens the focus to include not only those instructional activities, but also integration of learning across courses, fit with the university and degree choice, value of extracurricular activities, and reflection on personal mission and purpose. Tagg (2003) identified these aspects as qualities that produce thought-provoking, risk-taking, deep-introspective perusal to learning. By incorporating these learner-centered dimensions, we can provide a value-added process focused on what the student is learning throughout his or her unique educational experience. Weimer (2003) distinguishes between student-centered and learner-centered as a matter of responsibility. Being learner-centered provides the opportunity for students to be responsible for what they are doing with their educational process. By adopting the learner-centered perspective, students participate in deciding how to utilize the inputs and outputs of the university setting to shape a learning experience that achieves their goals.

\section{THE EDUCATIONAL EXPERIENCE AS AN EVOLVING WHOLISTIC PROCESS}

A student's experience through the sequential semesters leading to a college degree is incremental, evolving and complex. The learning experience is incremental by design in that course content later in a degree plan relies upon prior learning. Prerequisites often formally structure this sequencing. This incremental quality is important as it means that the effectiveness of current learning always depends upon the type and quality of an individual's previous experiences. The effectiveness of any current instruction and the meaningfulness of any new material is always supported or restrained by these experiences.

The evolving nature of the learning experience means that learning unfolds over time. New insights emerge in unpredictable ways. New perspectives are both the result of past experiences and the basis for new understanding. The complexity of these learning experiences results from the many influences that characterize college life. A variety of forces ranging from specific classroom experiences to general social relationships, personal health and family support interact to produce an overall experience that is profoundly unique to each student. These qualitiesincremental, evolving and complex — describe an interactive, wholistic system.

\section{DIMENSIONS OF THE EDUCATIONAL EXPERIENCE}

Any attempt to measure, track, understand or manage a complex system requires an approach that identifies important dimensions of the process, honors the uniqueness of the individual and is still able to respond meaningfully to changes as they occur (Priesmeyer, Murray, Koerner, Jensen and Sharp, 2000). We developed a specific model at our institution to support the learner-centered paradigm. Our model uses institutionally-appropriate questions to measure the student's educational experience across seven dimensions and non-linear methods to track and interpret changes in that experience over time. For our application we identified seven primary dimensions of the educational experience. For each of these we identified two attributes to measure. We developed our model's seven dimensions through a review of the current learner-centered perspective literature and to support our unique institutional environment.

Tagg (2003) describes the aspects of a learner-centered college as goals, activity, information, time horizon, community, and alignment. Alignment and Information were included as primary dimensions and combined goals and activity to develop an Assimilation dimension. Chickering and Gamson's $(1987 ; 1999)$ work on the Seven Principles for Good Practice in Undergraduate Education were also incorporated. The inclusion of Active Learning and Professionalism as primary dimensions was derived from their model. Additionally, Reynolds (2004) discussed the importance of connecting advising with the institution's mission, general education, self-reflection, and complexity. Therefore, we included Civic Engagement and Career Development to make the connection between the institution's mission and the student's community. Table 1 below provides a description of each dimension along with the specific indicators that measure the dimensions. 
Table 1

Primary Dimensions of Wholistic Education

\begin{tabular}{|l|l|l|}
\hline \multicolumn{1}{|c|}{ PRIMARY DIMENSIONS } & \multicolumn{1}{|c|}{ INDICATORS } & \multicolumn{1}{c|}{ DESCRIPTION } \\
\hline Assimilation & $\begin{array}{l}\text { Integration } \\
\text { Learning }\end{array}$ & $\begin{array}{l}\text { Ability to apply prior learning to current classes. } \\
\text { Believes learning a lot in classes. }\end{array}$ \\
\hline Active Learning & $\begin{array}{l}\text { Participation } \\
\text { Reflection }\end{array}$ & $\begin{array}{l}\text { Participating in class discussions. } \\
\text { Taking time to reflect on what was learned in class. }\end{array}$ \\
\hline Professionalism & $\begin{array}{l}\text { Timeliness } \\
\text { Quality of Work }\end{array}$ & $\begin{array}{l}\text { Always on time or early for commitments. } \\
\text { Quality of work meets or exceeds industry standards. }\end{array}$ \\
\hline Career Development & $\begin{array}{l}\text { Goal Clarity } \\
\text { Discussed Plans }\end{array}$ & $\begin{array}{l}\text { Developed specific long-term career plans. } \\
\text { Have discussed career plans with advisor. }\end{array}$ \\
\hline Civic Engagement & $\begin{array}{l}\text { Civic Activities } \\
\text { Civic Confidence }\end{array}$ & $\begin{array}{l}\text { Active in civic engagement activities. } \\
\text { Confidence gained through civic engagement activities. }\end{array}$ \\
\hline Alignment & $\begin{array}{l}\text { University Alignment } \\
\text { Major Alignment }\end{array}$ & $\begin{array}{l}\text { Knowing this university is the right one. } \\
\text { Knowing the chosen major is the right one. }\end{array}$ \\
\hline Information & $\begin{array}{l}\text { Advisor Effectiveness } \\
\text { Support Services }\end{array}$ & $\begin{array}{l}\text { Confidence advisor can supply information. } \\
\text { Actively using university services. }\end{array}$ \\
\hline
\end{tabular}

The dimensions of Assimilation and Active Learning address a student's cognitive effort and active participation in the learning process. Professionalism and Career Development measure the extent to which behaviors and quality of work match professional expectations and the extent to which the student has developed career goals. The dimensions of Civic Engagement and Alignment provide measures to indicate the level of civic engagement activities and the sense of being at the right university taking the right major. Finally, the Information dimension captures the importance of student satisfaction with faculty and with other service departments on campus.

The model also combines some of the individual indicators in different ways to allow for the development of some informative secondary dimensions, which can provide additional insight about individual students. Through both the primary and secondary dimensions students can identify the complexity and interdependence of their education and engage in creating wholeness for themselves. Table 2 below provides a list of the secondary dimensions along with the various indicators used to construct each.

Table 2

Secondary Dimensions of Wholistic Education

\begin{tabular}{|l|l|}
\hline SECONDARY DIMENSION & \multicolumn{1}{|c|}{ INDICATORS } \\
\hline Student Experience Score & All Dimensions \\
\hline Academics & Integration, Learning, Participation, Reflection, and Support Services \\
\hline Focus & Timeliness, Quality of Work, Goal Clarity, Discussed Plans, and Major Alignment \\
\hline Cerebration & Integration, Learning, and Reflection \\
\hline Interaction & Participation, Civic Activities, and use of Support Services \\
\hline
\end{tabular}

\section{TRACKING THE EDUCATIONAL EXPERIENCE}

To track individual student experiences over time we developed a computer program that provides feedback on all the dimensions in our model. The program is implemented the first time a student visits a faculty advisor. During this visit the student performs a self-assessment by responding to a fourteen-item questionnaire (see Appendix A). The initial responses to the questionnaire establish a baseline that measures the student's overall educational experience at the time of the initial visit.

While there is considerable value in reviewing the scores from an initial assessment, the real value of this program becomes apparent during subsequent assessments which can be initiated at any time by the student or the 
faculty advisor. The dynamic quality of the learning experience emerges over time as we examine and interpret changes in all of the dimensions.

In order to capture the wholistic nature of the student's educational experience, it is necessary to assess the interdependencies in the model's dimensions. Nonlinear systems theory provided the methods we needed to assess the student's evolving educational process (Murray, Priesmeyer and Madison, 2002). One specific nonlinear tool used in the program is the phase plane, which depicts the incremental, emergent interaction of any two dimensions of a system. Figure 2 provides a phase plane depicting the interaction of two dimensions. Specifically, it plots the changes in the components of the dimension "Professionalism" which we defined as the Quality and Timeliness of work. The first measurement of these dimensions provides a baseline and each subsequent measurement is then compared to the prior measure.

Figure 2

Phase Plane Relating Changes in Quality of Work and Timeliness

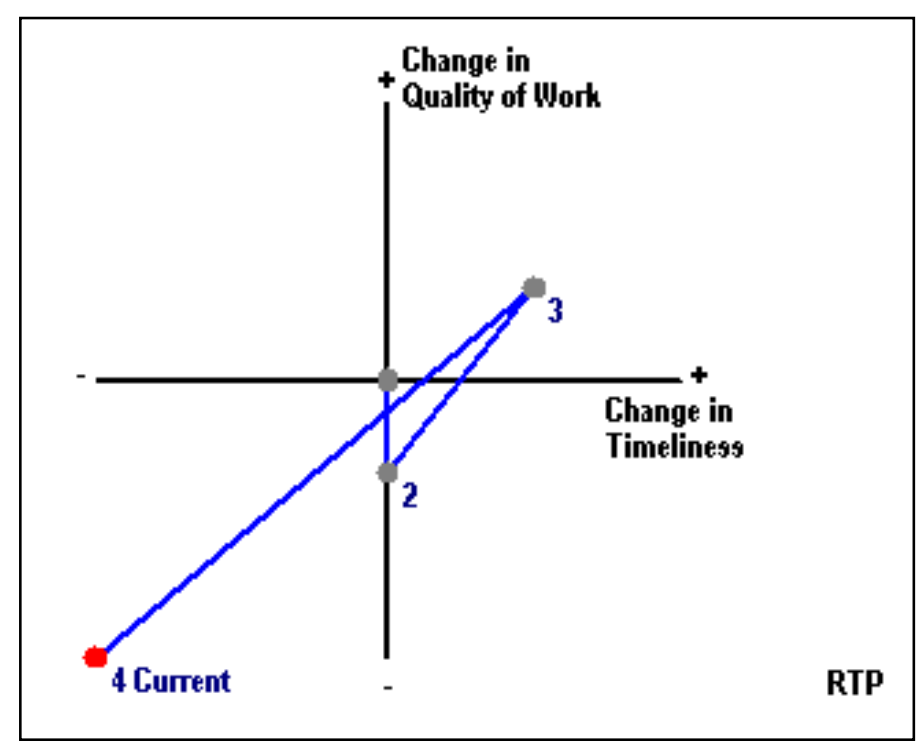

For example, if a student's Quality of Work declines but Timeliness is unchanged after the first assessment then a position like the one labeled " 2 " in Figure 2 can be plotted below the origin on the vertical axis. If the student reports that both Quality of Work and Timeliness have improved in the third assessment then a position like the one labled " 3 " in the upper right quadrant (i.e., Quadrant 1) can be plotted depicting increases in both of these measures. Similarly, if a student is less timely and reports lower Quality of Work in the fourth assessment then a position like the one labeled "4 Current" can be plotted in the lower left quadrant (Quadrant 3). Extending a line from each plotted point to the next provides a trajectory indicating how the student's experience has evolved over the period of the four assessments (Priesmeyer and Sharp, 1995).

\section{INTERPRETING EXPERIENTIAL DYNAMICS}

While the phase plane offers a graphical view of the student's experience, the important information provided by the evolving trajectory is the designation of the quadrants the system visits. These quadrants constitute the set of mutually exclusive and exhaustive states. Additionally, because the changes in states are made evident at each measurement this approach provides for early recognition of desirable changes that should be reinforced and undesirable changes that call for intervention. In a similar manner, all the interacting dimensions that the students experience can be mapped as combinations on multiple phase planes. Rather than relying on comparisons to standardized populations or computations that attempt to identify a trend, this approach defines each change in 
behavior and can provide a description of that change. Interpreting those behaviors, as indicated in Table 2, allows for the development of institutionally-appropriate educational strategies, as shown in Table 3 below.

Table 3

Phase Plane Interpretations

\begin{tabular}{|l|l|l|}
\hline \multicolumn{1}{|c|}{ QUADRANT } & \multicolumn{1}{|c|}{ DESCRIPTION } & \multicolumn{1}{c|}{ STRATEGIES } \\
\hline $\begin{array}{l}\text { QUADRANT 1 } \\
\text { Upper Right }\end{array}$ & $\begin{array}{l}\text { Both Quality of Work } \\
\text { and Timeliness have } \\
\text { improved. }\end{array}$ & $\begin{array}{l}\text { Your level of professionalism has improved. SUGGESTION: } \\
\text { Determine what changes you made that improved your ability to } \\
\text { arrive on time and produce higher quality work. Discuss with } \\
\text { someone these changes and how you can continue them. }\end{array}$ \\
\hline $\begin{array}{l}\text { QUADRANT 2 } \\
\text { Upper Left }\end{array}$ & $\begin{array}{l}\text { Quality of Work has } \\
\text { improved while } \\
\text { Timeliness has declined. } \\
\text { Qhile the quality of your work has improved, professionalism also } \\
\text { demands that you are able to meet your commitments on time. } \\
\text { SUGGESTION: Get and use a time organizer (i.e., planner) and } \\
\text { take a TIME MANAGEMENT workshop at the LAC or elsewhere. }\end{array}$ \\
\hline $\begin{array}{l}\text { Buth Quality of Work } \\
\text { and Timeliness have } \\
\text { declined. }\end{array}$ & $\begin{array}{l}\text { Unfortunately, your professionalism has declined. You are less } \\
\text { likely to arrive at commitments on time and the quality of your } \\
\text { work is less acceptable relative to industry standards. } \\
\text { SUGGESTIONS: (1) Sign up for a TIME MANAGEMENT } \\
\text { workshop at the LAC or elsewhere and (2) discuss with LAC } \\
\text { counselors possible strategies for improving the quality of your } \\
\text { work. }\end{array}$ \\
\hline $\begin{array}{l}\text { QUADRANT 4 } \\
\text { Lower Right }\end{array}$ & $\begin{array}{l}\text { Your professionalism has declined due to a decrease in the quality } \\
\text { of your work. While it is important to be on time for your } \\
\text { commitments, your work needs to meet or exceed standards in } \\
\text { industry. SUGGESTIONS: (1) Identify how and why the quality of } \\
\text { your work has declined and then (2) meet with LAC counselors to } \\
\text { discuss this issue and formulate work improvement strategies. }\end{array}$ \\
\hline
\end{tabular}

Similar analysis of all of the dimensions in the model produces a collection of strategies that, taken together, produce a Progress Report after each assessment (Priesmeyer, Sharp, Wammack and Mabrey, 1996). Appendix B provides a sample report that is unique to each student at each assessment. The report offers a kind of "third person" opinion that places the faculty member and the student in partnership roles, discussing the report and recommending actions for improvement. It pertains to the student individually and tracks that student throughout the university experience.

The Progress Report is used to drive discussions with the student and, when appropriate, it is used to encourage the student to follow-up with specific activities. Areas in which the student perceives to be performing well or has improved are discussed. Questions can be asked such as "What do you feel you are doing to assure that you are successful in this area?" "How would you like to improve?" "What would you do in order to improve?" The student is guided to focus on the areas perceived as weak or declining. For example, a student could use the report's suggestion to visit the Office of Career Services if the program indicated a decrease in Major Alignment.

\section{CONCLUSIONS}

Although a student's educational experience evolves continually while in college, faculty advisors have only limited and periodic opportunities to discuss that progress with individual students. As a result, an advisor's understanding of a student's status at any time is quite limited. Our model provides for a continuity of information through this experience. It constitutes a resource for both the student and the advisor in that it retains information about the student's prior status and repeatedly interprets the student's progress.

From our experience with this model, we have learned that it does make meaningful contributions to student advising sessions. The Progress Reports provide opportunities to discuss issues important to the education that might not otherwise be addressed. The suggestions provided in the reports allow advisors and students to 
identify specific activities that enhance the overall educational experience. The metrics provided by the reports challenge some students to create a richer, more wholistic education for themselves.

Although the model described here was designed for our institution, we believe it has the basic attributes that are essential to fostering a wholistic, learner-centered education. It is individualized, multidimensional, integrative, dynamic (e.g., sensitive to changes), and supportive of reflection and student-ownership of the educational experience. Most importantly, this approach allows advisors and students to learn together. Advisors learn more about the interests, abilities and needs of individual students and the students learn more about how to successfully integrate the many elements of an education.

\section{AUTHOR INFORMATION}

All three authors are faculty at the Bill Greehey School of Business, St. Mary's University in San Antonio, Texas. H. Richard Priesmeyer, Ph.D. is a professor of management with a research track in nonlinear methods. Stephanie Ward, Ph.D. is director of the Bill Greehey Scholar program and teaches Organizational Behavior and Human Resources. Her research explores questions about rewards, psychological contracts, and organizational justice. Mary Ann Murray, Ph.D. is Associate Dean of the Bill Greehey School of Business; her research interests focus on project management and process improvement.

\section{REFERENCES}

1. Chickering, A.W., \& Gamson, Z.F. (1987). Seven principles for good practice in undergraduate education, AAHE Bulletin, 39, 3-7.

2. Chickering, A.W., \& Gamson, Z.F. (1999). Development and adaptations of the seven principles for good practice in undergraduate education, New directions for Teaching and Learning, 80, 75-81.

3. Murray, Mary Ann, H. Richard Priesmeyer and Thomas Madison ANonlinear Analysis of the Educational Environment: An Innovative Approach to Assessment Journal of the Academy of Business Education, 3 (2002), 15-25.

4. Priesmeyer, H. Richard, Mary Ann Murray, JoEllen Koerner, Gwen Jensen and Lawrence F. Sharp Nonlinearity as an Approach to Business Process Reengineering Business Process Management Journal, 6, (No. 4, 2000), 304-313.

5. Priesmeyer, H. Richard and L.F. Sharp, L. Wammack and J. D. Mabrey AChaos Theory and Clinical Pathways: A Practical Application Journal of Quality Management in Health Care, 4 (No. 4, 1996), 63-72.

6. Priesmeyer, H. Richard and Larry Sharp Phase Plane Analysis: Applying Chaos Theory in Health Care Journal of Quality Management in Health Care, 4 (No. 1, 1995), 62-70.

7. Reynolds, M. (2004, June). Faculty advising in a learner-centered environment: A small college perspective, Academic Advising Today, 27, 2.

8. Seigfried, Ray, H. Richard Priesmeyer and Mary Ann Murray "The Supply as a Wholistic System: A Case Study" The International Conference on Systems Thinking in Management (University of Pennsylvania), May, 2004.

9. Tagg, J. (2003). The learning paradigm college. Bolton, MA: Anker Publishing company, Inc.

10. Tagg, J., \& Barr, R.B. (1995). From teaching to learning - a new paradigm for undergraduate education, Change, 27, 12-26.

11. Weimer, M. (2003). Focus on learning, transform teaching. Change, 35, 49-54. 
Appendix A

Wholistic Educational Experience Questionnaire

Consider your experiences since the previous assessment and answer each question by marking a value according to the following scale.

\begin{tabular}{|c|c|c|c|}
\hline (1)Strongly Disagree & (2) Disagree & (3)Somewhat Disagree & (4) Neither (or don't know) \\
\hline
\end{tabular}

To what extent do you agree with each of the following...

1. I am able to integrate what I learn from various classes.

2. I am learning a lot in my classes.

3. I actively participate in class discussions.

4. I always take time to reflect on what I learn in class.

5. I am always on time or early for my commitments.

6. The quality of my work meets or exceeds standards in industry.

7. I have specific long-term career plans.

8. I have discussed my career plans with my advisor.

9. I am actively involved with civic engagement or service learning activities.

10. My civic engagement activities have increased my confidence in myself (if none, answer 1).

11. I know this university is the right one for me.

12. I know that the major I selected is the right one for me (if undeclared answer 1)

13. I feel confident that I can get the information I need from my advisor.

14. I actively use university programs and services (such as Career Services, Campus Ministries, Student Life, Learning Assistance Center, etc.). 


\section{Appendix B \\ Progress Report}

\begin{tabular}{|c|c|}
\hline Advisee: & 23435 \\
\hline Assessed: & 3/15/2007 2:14 PM \\
\hline
\end{tabular}

This STUDENT'S EXPERIENCE at the university has improved from $55.55 \%$ to $68.05 \%$.

Below is an analysis of the changes in the learning experience since the prior assessment.

ASSIMILATION

INTEGRATION has decreased but LEARNING has increased. While you feel you are learning more and that's good, you have been less able to connect the learning across your classes. SUGGESTION: Have a conversation with someone about two or more classes and discuss how those classes relate to each other.

ACTIVE LEARNING

CONGRATULATIONS! Both PARTICIPATION and REFLECTION have increased. You have been more actively participating in class and you have been taking time to reflect on what you learn. Keep up the good work. These behaviors are essential to learning so continue them and consider even more participation and reflection.

\section{PROFESSIONALISM}

Both TIMELINESS and QUALITY OF WORK have decreased. Unfortunately, your professionalism has declined. You are less likely to arrive at commitments on time and the quality of your work is less acceptable relative to industry standards. SUGGESTIONS: (1) Sign up for a TIME MANAGEMENT workshop at the LAC or elsewhere and (2) discuss with LAC counselors possible strategies for improving the quality of your work.

\section{CAREER DEVELOPMENT (-)}

GOAL CLARITY has remained the same but discussion of CAREER PLANS with your advisor has declined. SUGGESTIONS: (1) Discuss your career plans with your advisor and (2) visit the Career Services Center to discuss your career interests and how you can become better prepared for placement after graduation.

\section{CIVIC ENGAGEMENT}

CONGRATULATIONS! Your CIVIC ENGAGEMENT ACTIVITY has increased and you feel more confident as a result of these activities. Continue finding ways to serve your community and relate your activities to your long term goals.

\section{ALIGNMENT}

CONGRATULATIONS! Both your UNIVERSITY ALIGNMENT and your MAJOR ALIGNMENT have increased. You are more confident you have chosen the right university and the right major for yourself. SUGGESTION: Reflect on the reasons why this university and major are appropriate for you and discuss the reasons with someone.

\section{INFORMATION}

CONGRATULATIONS! Both ADVISOR EFFECTIVENESS and use of university SUPPORT SERVICES have increased. You are feeling more confident you can get the information you need from your advisor and you are using university services more frequently. SUGGESTION: Discuss with your advisor the university services you have been using (Career Services, Campus Ministries, Student Life, Learning Assistance Center, or other).

SPECIAL INDICATORS (See Baseline report for definitions of the following. Read Previous/Current.) STUDENT EXPERIENCE indicator ( 55.55 ) / ( 68.05 ), ACADEMICS indicator ( 53.33 ) / ( 73.33 ), FOCUS indicator ( 66.66 ) / ( 63.33 ), CEREBRATION indicator ( 50 ) / ( 66.66 ), INTERACTION indicator ( 55.55 ) / ( 77.77 ), CI-SCORE ( 27.77$) /(51.85)$. 